\title{
METHODOLOGY FOR THE OPTIMIZATION OF GROUNDWATER QUALITY MONITORING NETWORKS ORIENTED TO SATISFY A SPECIFIC SPATIAL COVERAGE
}

\author{
ACEVES-DE-ALBA, J. ${ }^{1,2}$ - JÚNEZ-FERREIRA, H. E. ${ }^{1 *}$ - GONZÁLEZ-TRINIDAD, J. ${ }^{1}$ - CARDONA-

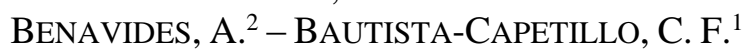 \\ ${ }^{I}$ Doctorado en Ciencias de la Ingeniería, Universidad Autónoma de Zacatecas, Av. Ramón \\ López Velarde No. 801, Col. Centro, Zacatecas, Zacatecas, México, C.P. 98000 \\ (phone: +52-492-924-2432; fax: +52-492-925-6690 ext. 1613) \\ ${ }^{2}$ Facultad de Ingeniería, Universidad Autónoma de San Luis Potosí, Av. Dr. Manuel Nava No. \\ 8, Zona Universitaria Poniente, San Luis Potosí, San Luis Potosí, México, C.P. 78290 \\ (phonelfax: +52-444-826-2300) \\ *Corresponding author \\ e-mail:hejunez@uaz.edu.mx
}

(Received $19^{\text {th }}$ Mar 2019; accepted $3^{\text {rd }}$ May 2019)

\begin{abstract}
Through the optimal design of groundwater monitoring networks, it is possible to obtain the maximum level of information for certain variables (water level, some quality indicator parameters, and/or the presence of some contaminant) at minimum cost; the methodologies for this kind of designs follow a procedure to discard wells that provide redundant information. The information collected by monitoring networks is fundamental for supporting decision making that aims for a sustainable management of groundwater. In this paper, an existing methodology for the design of optimal groundwater quality monitoring networks is modified to include a new algorithm that allows to obtain alternative spatial distributions of the wells that provide the highest level of information, expressed in terms of the estimated uncertainty over an estimation grid. Additionally, different weights can be assigned to each monitoring site and to the analyzed variable(s) within the objective function in order to accomplish specific objectives without a significant loss of information. The final result represents a significant improvement to the original methodology by adjusting the spatial coverage of the optimal monitoring network to satisfy specific objectives.
\end{abstract}

Keywords: geostatistics, Kalman filter, estimation grid, water management, sustainable

\section{Introduction}

Groundwater is a vital resource for human beings; it provides $50 \%$ of the total water used worldwide (WWAP, 2016). This data shows the dependence of people on groundwater, mainly in regions with extensive cropping areas for food production and industrial activities (Li et al., 2015).

Considering the importance of groundwater, it is necessary to know, in detail, the spatial distribution of the groundwater flow systems and its physical-chemical characteristics to improve its management (Esquivel et al., 2015; Kim et al., 2007). It is relevant to assure sustainable levels of groundwater quality when it is used for water supply (Yang et al., 2018). The implementation of groundwater quality monitoring programs is of paramount importance; for instance, it was detected that in almost $15 \%$ of the monitoring stations in Europe, the standard for nitrates in drinking water established by the World Health Organization (WHO) was exceeded (WWAP, 2018). It is possible to characterize the groundwater quality in some areas of interest (AOI) by measuring some physical-chemical parameters of water extracted by wells and 
estimating the spatial distribution of their concentrations; however, the costs and time involved in visiting and sampling all the existing wells are often not economically viable; specially in low income countries.

The optimal design of groundwater monitoring networks is an alternative to reduce time and costs associated to the acquisition of data to accomplish specific objectives (Júnez-Ferreira et al., 2016a); in addition the development of a sustainable strategy for groundwater extraction management is required.

The methodologies for the optimal design of groundwater monitoring networks can be subdivided in three main groups: 1) those based on elements of hydrogeological conceptual models, 2) those that execute data analysis with statistical techniques, and 3) those that use groundwater flow numerical models (Júnez-Ferreira et al., 2016a; Loaiciga et al., 1992; Herrera and Pinder, 2005; Zhang et al., 2005). The latter can be considered as the most robust framework, since it does not only consider hydrogeological aspects (as group one) but also takes into consideration groundwater levels evolution (in space and time). It is important to note that some methodologies combine aspects of two or the three groups.

The hydrogeological framework usually uses a Geographic Information System (GIS) in order to incorporate as much areal information as possible of the hydrogeological factors that control the groundwater functioning such as geology, recharge and discharge zones, rainfall data, groundwater levels, land use/land cover images derived from satellites, among others (Singh and Katpatal, 2017; Zhou et al., 2013). The statistical-based methodologies usually employ a variance-based objective function evaluated by an optimization method, they are commonly based on spatial and/or spatiotemporal geostatistical techniques, entropy theory, harmonic series models and principal component analysis (Mirzaie-Nodoushan et al., 2017; Júnez-Ferreira et al., 2016b; Andricevic, 1990; Kim et al., 2007; Júnez-Ferreira and Herrera, 2013), some of them are multicriteria (Hosseini and Kerachian, 2017a, b). The combination of hydrogeological criteria through the use of GIS and statistical techniques has been used in (Baalousha, 2010; Uddameri and Andruss, 2014; Sizirici and Tansel, 2015; JúnezFerreira et al., 2016a; Alizadeh and Mahjouri, 2017). The methodologies based on a numerical flow model include optimization methods and are always combined with a GIS (Kim, 2015) or with statistical estimation methods such as the Kalman Filter (KF), Monte Carlo simulations (Herrera and Pinder, 2005; Zhang et al., 2005; Kollat et al., 2011; Luo et al., 2016; Jiang et al., 2018), or can have characteristics of the three groups of methodologies for the optimal design of groundwater monitoring networks (Nobre et al., 2007).

Most of these methodologies require a large amount of information about the study site that includes a comprehensive database of sampling campaigns, geological data, and an advanced understanding of flow systems.

In those areas with scarce data, it is necessary to implement methodologies to start with the data generation. In the literature, the KF or different types of kriging have been widely used as estimation methods for the design of optimal monitoring networks oriented to the reduction of the estimate error variance in areas with few hydrogeological data (Júnez-Ferreira et al., 2016a; Júnez-Ferreira and Herrera, 2013); however, the spatial distribution of the wells with higher priority selected by these methodologies preferably covers the central area of a pre-defined estimation grid, frequently assigning a lower priority to those wells located at the periphery of the study area. This is considered as a deficiency because a poor spatial coverage of the 
monitoring network may lead to the undesirable extrapolation of the monitored variable(s) at those areas. In addition, a resilient monitoring network in regard to sampling station distribution, in practice could be easier to implement and to explain to stakeholders. The design of an optimal monitoring network results in an academic exercise not feasible to real-world limitations (data availability, budget), hence the implementation of alternative methodologies is advisable (Bode et al., 2018).

In Mexico there are 653 administrative aquifers, 105 of them have been classified with intensive abstraction resulting in negative environmental effects such as the ongoing deterioration of water quality (Esteller et al., 2011), sea water intrusion problems, presence of brackish water (CONAGUA, 2017), and high fluoride and arsenic concentrations in groundwater (Banning et al., 2012; Cardona et al., 2018). However, the natural evolution of the groundwater quality has not received the required attention as a tool for management planning.

Mexico and a number of countries around the world are involved in the Sustainable Development Goals (SDG) to address global challenges such as environmental (water) degradation. Specifically, goal 6: Clean Water and Sanitation, indicator 6.3.2: Proportion of water bodies with good water quality requires the implementation of groundwater monitoring networks to compile data for some core parameters at existing sampling stations (UN WATER).

The lack of properly designed wells for groundwater quality monitoring purposes makes necessary employing the available long screened production wells. The spatial distribution of these production wells depends on factors such as the location of irrigation lands and populated areas. Therefore, it is relevant for water management institutions to consider methodologies that contribute to the design of optimal groundwater monitoring networks, with water quality data obtained from production wells. This is an important issue for making decisions regarding groundwater sustainable development, not only in Mexico, but in several other countries around the world.

This paper proposes a methodology for the design of multivariable groundwater monitoring networks. The approach includes 1) irregular shape estimation grid according with the spatial sampling station distribution 2) a ponderation grid map based on sampling station density per unit area 3) the definition of an objective function that considers simultaneously, the ponderation grid map, priority determination for any water quality parameters included in the monitoring network and/or for sampling stations and a KF for the reduction of the estimate uncertainty for each variable provided by the selected sampling stations. The methodology allows obtaining alternative spatial distributions of the wells that provide the highest level of information, expressed in terms of the estimated uncertainty over an estimation grid.

\section{Materials and methods}

The methodology presented in this paper is based on that proposed in Júnez-Ferreira et al. (2016a); the original methodology selects the optimal monitoring positions by using spatial correlations expressed as covariance matrices derived from semivariogram models obtained through geostatistical analyses to data of groundwater quality parameters. The optimization of the monitoring network is carried out by successive inclusions employing the $\mathrm{KF}$ as the estimation method, minimizing a function called the joint total (JT) normalized variance of the estimation error (Júnez-Ferreira et al., 2016a). 
This methodology requires of a spatial estimation grid where the objective function is evaluated. During the optimization process, the addition of weights to the groundwater quality parameters, or different densities in the estimation grid have been useful to satisfy specific objectives, like assigning a higher priority to contaminated sites or to highly dangerous parameters (Júnez-Ferreira et al., 2016a; Esquivel et al., 2015).

For the proposed methodology, the objective function incorporates the spatial coverage of the available sampling stations (by means of a supplementary function, SF) besides a modified version of the joint total (JT) normalized variance of the estimation error. The modified JT, besides having a weight for each groundwater quality parameter includes a weight for each sampling station, this new algorithm is now called the weighted joint total normal variance of the estimation error (WJT). Both, the WJT and the SF are weighted in order to define different alternatives of the spatial coverage for the selected monitoring networks without a significant loss of information.

The objective function $(O F)(E q .1)$ for the proposed methodology is:

$$
O F=\mathrm{V} \times \mathrm{WJT}+W \times \mathrm{SF}
$$

where $V$ and $W$ are the weigthing factors for the WJT and the SF, respectively; $V+W=1$. Based in Júnez-Ferreira et al. (2016a) to obtain WJT, the KF is implemented through the use of $\hat{\mathrm{q}}^{0}$ and $\mathrm{P}^{0}$ that represent an initial state vector and the initial error covariance matrix, respectively. The KF process employs the following equations (Eqs. 2, 3 and 4):

$$
\begin{gathered}
\hat{\mathrm{q}}^{\mathrm{n}+1}=\hat{\mathrm{q}}^{\mathrm{n}}+\mathrm{K}_{\mathrm{n}+1}\left(\mathrm{z}_{\mathrm{n}+1}-\mathrm{H}_{\mathrm{n}+1} \hat{\mathrm{q}}^{\mathrm{n}}\right) \\
\mathrm{P}^{\mathrm{n}+1}=\mathrm{P}^{\mathrm{n}}-\mathrm{K}_{\mathrm{n}+1} \mathrm{H}_{\mathrm{n}+1} \mathrm{P}^{\mathrm{n}} \\
\mathrm{K}_{\mathrm{n}+1}=\mathrm{P}^{\mathrm{n}} \mathrm{H}_{\mathrm{n}+1}^{\mathrm{T}}\left(\mathrm{H}_{\mathrm{n}+1} \mathrm{P}^{\mathrm{n}} \mathrm{H}_{\mathrm{n}+1}^{\mathrm{T}}+\mathrm{r}_{\mathrm{n}+1}\right)
\end{gathered}
$$

where $\mathrm{K}_{\mathrm{n}+1}$ is the Kalman gain, $\mathrm{H}_{\mathrm{n}+1}$ is the sampling matrix, $\mathrm{z}_{\mathrm{n}+1}$ is the measurement vector, and $r_{n+1}$ is the measurement error covariance. Superscripts refer to the number of measurements employed in the estimation; subscripts are used to indicate the transition when a new measurement is going to be used in the process.

The spatial covariance matrix for each parameter is calculated as follows (Eq. 5):

$$
C(h)=C(0)-\gamma(h)
$$

where $C(h)$ represent the covariance matrix, $c(0)$ is the variance for each analyzed parameter, and $\gamma(h)$ is the variogram model function.

The WJT value is calculated with (Eq. 6):

$$
\mathrm{WJT}=\sum_{p=1}^{n p} \sigma_{w, p}^{2} \times \alpha_{w} \times \alpha_{p}
$$

where $\sigma_{\mathrm{w}, \mathrm{p}}^{2}$ represents the normalized estimate error variance (located at the principal diagonal of the corresponding updated covariance matrix) at each estimation position 
for the p parameter, when the $\mathrm{w}$ well has been sampled, $\alpha_{\mathrm{w}}$ represents the $\mathrm{w}$ well weight, $\alpha_{\mathrm{p}}$ represents the p parameter weight, and $n \mathrm{p}$ is the number of parameters.

The main advantages of this proposal are: a) it considers the possibility of obtaining alternative monitoring networks designs oriented to a desired spatial coverage b) it allows the assignation of different weights to a particular sampling point, which gives the opportunity to take into account specific hydrogeological conditions such as contaminated areas without affecting, within the optimization procedure, those wells located around this specific sampling point.

\section{Custom estimation grid}

As part of the proposed methodology, it has been developed an algorithm for the generation of a custom estimation grid (CEG). The KF estimates will be obtained and the OF evaluated at the CEG; it offers advantages when compared to a regular grid as implemented in commercial software such as XTools Pro 18 (XTools Pro), create fishnet (ArcGIS) and sampling design tool (Buja, 2012) because it avoids extrapolation areas since it is an adjusted envelope of the sampling points.

The definition of the CEG starts with the calculation of the distance between the extreme coordinates of the wells (maximum distance), followed by the calculation of the grid density with half the maximum distance divided by ten; this density (separation between the grid nodes) is selected to draw a rectangular grid that covers all the area where the wells with available data are located, an initial value of 0 is set to all these nodes. The CEG will be composed by values different than 0 , the following procedure is carried out from the top (North) to the bottom (South) row of the original rectangular grid to the assignation of these values:

1. Values of 1 are assigned to the nodes that are next to the wells.

2. For each row it is given a value of 2 to the nodes that are between those with a value of 1 .

3. A value of 3 is assigned to the nodes in empty rows to connect the nodes with values different to 0 .

4. Values of 4 will be assigned to the nodes with an original value of 0 in such a manner that each row of the CEG cannot be longer one node to the West and one node to the East than the next row at the south.

The flowchart and pseudocode for this process are shown in Figure 1.

The colours in Figure 2 are directly related to the value that indicates in which part of the algorithm the node for the CEG was selected.

\section{Supplementary function}

For the case study, the SF is proposed trying to establish a higher priority to those wells that have influence over the highest number of nodes of the estimation grid, and at the same time, with small influence of the other wells on their estimates (i.e., there is a poor spatial coverage of wells at that area). For that purpose, it is necessary to define a Custom Smooth Grid (CSG) based on the CEG and the maximum range used in the semivariogram models. For each node of the CEG, it is calculated the sum of wells located at a distance less than the model range, obtaining the values of the CSG (Fig. 3). 


$$
\text { - } 10866 \text { - }
$$

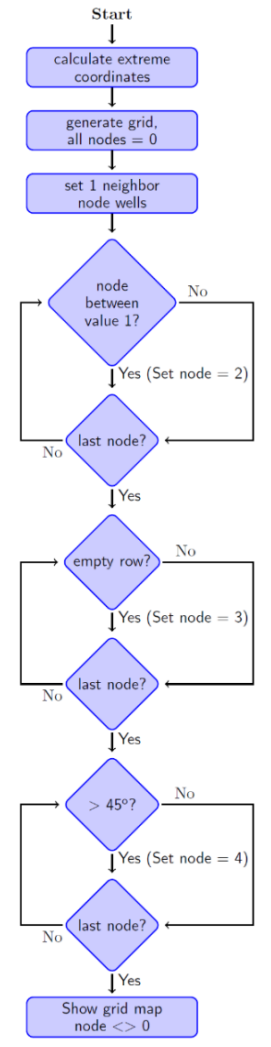

Calculate extreme coordinates based on the sampling stations

$$
\text { Initialize estimation grid (EG) to } 0
$$

While the EG node counter is less or equal to the total EG nodes

While the sampling station counter is less or equal to the total sampling stations

If the EG node is neighbor to the sampling station

$$
\text { Set EG node to } 1
$$

While the EG node counter is less or equal to the total EG nodes

If the EG node is between EG nodes equal to 1 in the same row

$$
\text { Set } 2 \text { to the EG node }
$$

While the EG node counter is less or equal to the total EG nodes

$$
\text { If all the row is } 0 \text { in the EG }
$$

$$
\text { Identify and sum the continuos rows with } 0
$$

Calculate the EG nodes per row based on the position and the rows with 0

While the row counter is less or equal to total rows with 0

While the number of node is less or equal to the number of nodes

$$
\text { Set the EG node to } 3
$$

While the grid node counter is less or equal to the total grid nodes

If previous and next position in the EG node is different to 0

$$
\text { If a below position is } 0
$$

Set 4 to the below EG node

While the EG node counter is less or equal to the total EG nodes If the EG node is different to 0

Display EG node: pink (1), blue (2), brown (3) and green (4)

Figure 1. CEG generation flowchart and pseudocode

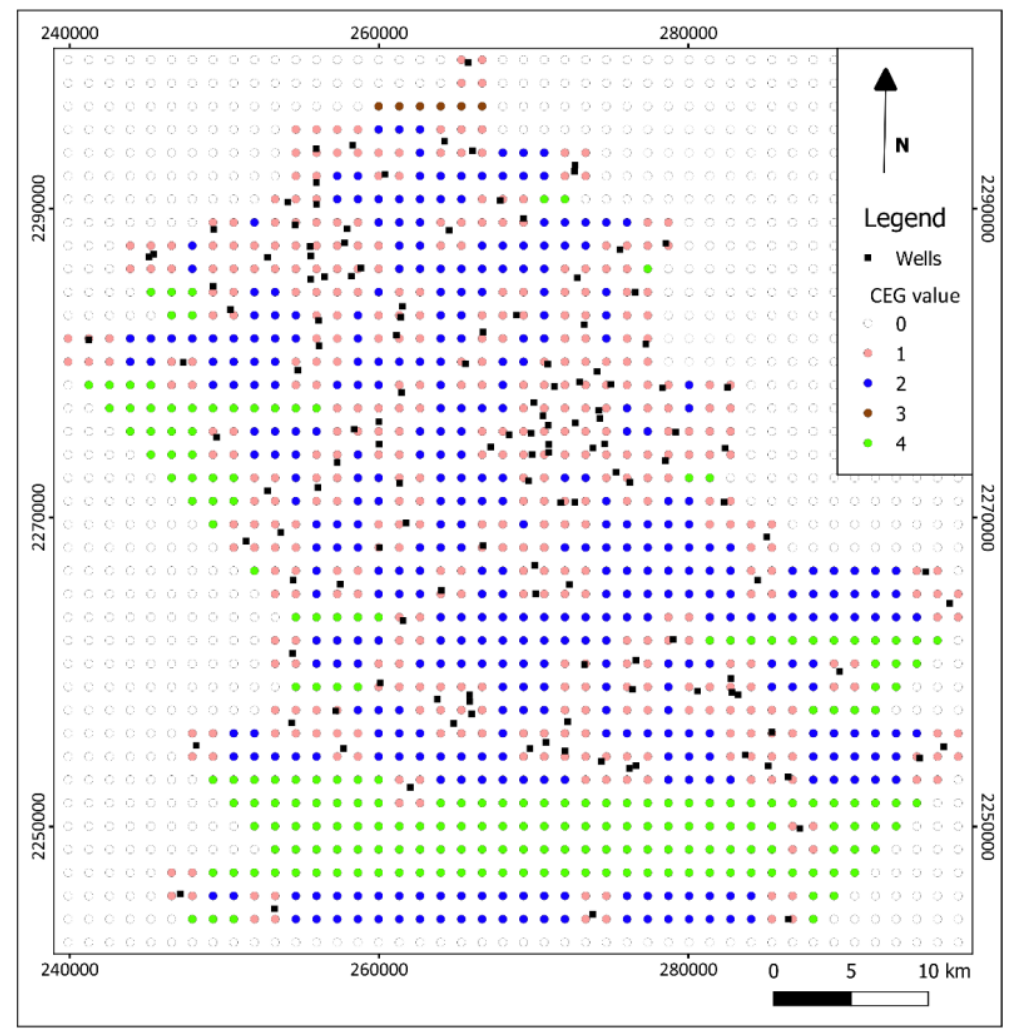

Figure 2. Custom estimation Grid (CEG)

APPLIED ECOLOGY AND ENVIRONMENTAL RESEARCH 17(5):10861-10882. http://www.aloki.hu • ISSN 15891623 (Print) • ISSN 17850037 (Online) DOI: http://dx.doi.org/10.15666/aeer/1705_1086110882 (c) 2019, ALÖKI Kft., Budapest, Hungary 


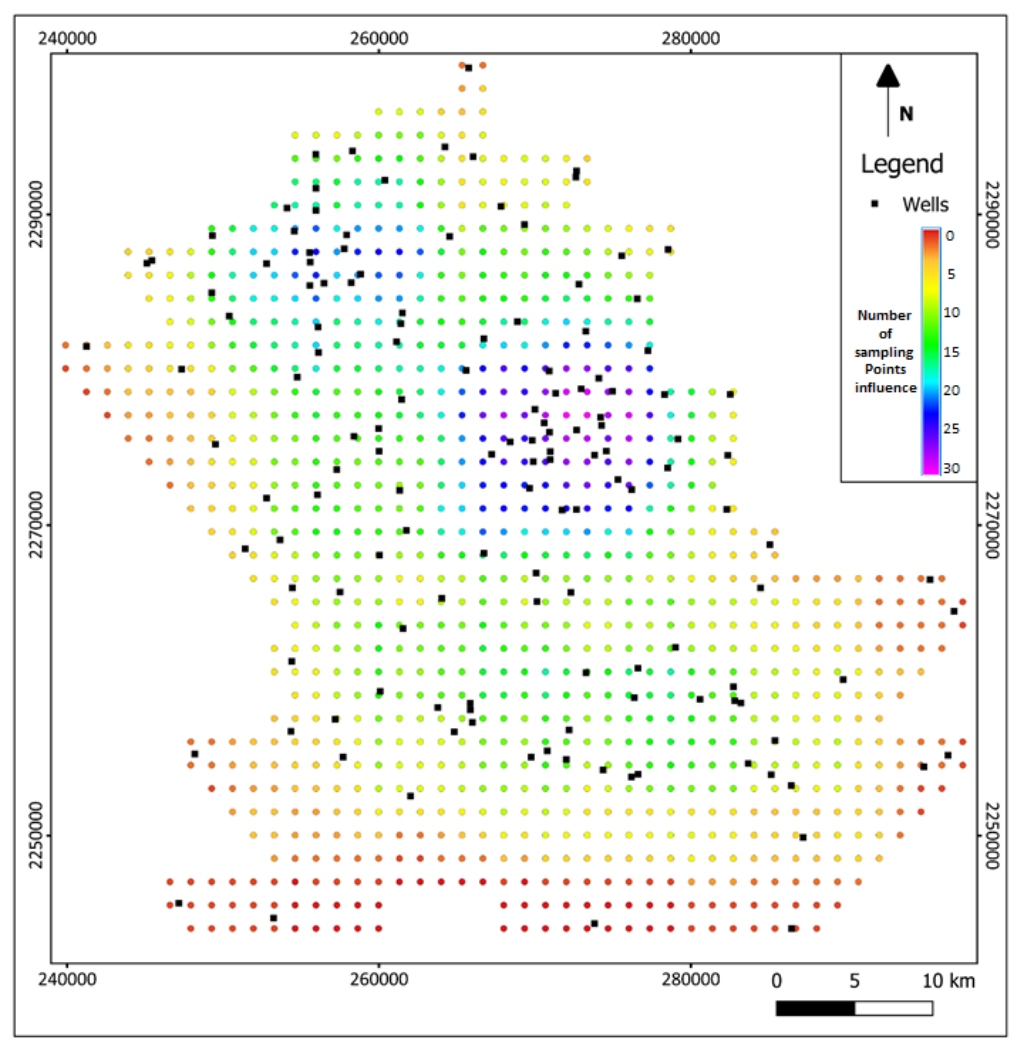

Figure 3. Custom Smooth Grid (CSG)

The SF is defined as follows:

The lower values in the CSG represent zones with a poor spatial coverage of wells.

The formulas for the values of the CSG are (Eq. 7):

$$
i e_{w, p}=\sum_{n=1}^{n n} n o d e_{n}
$$

where $i e_{w, p}$ represents the influence of the well $w$ over the nodes of the CEG, corresponding to the $p$ parameter, node $e_{n}$ is 1 when the node is inside a circumference with center on the $w$ well and radius equal to the range of the semivariogram model in the $p$ parameter; node $_{n}$ is 0 when the node is outside the circumference, $n n$ is the total number of nodes in the CEG (Eq. 8);

$$
i w_{n, p}=\sum_{w=1}^{n w} w e l l_{w}
$$

where $i w_{n, p}$ represents the influence of the sampling wells over the node $n$, corresponding to the $p$ parameter, well $l_{w}$ is 1 when the well is inside a circumference with center on the $n$ node and radius equal to the range of the semivariogram model in 
the $p$ parameter, well $l_{w}$ is 0 when the well is outside that circumference, $n w$ is the total number of sampling wells (Eq. 9);

$$
i n w_{w, p}=\sum_{n=1}^{n n}\left(i w_{n, p} \times r_{n, p}\right)
$$

where $i n w_{w, p}$ represents the influence of the sampling wells over circular zones of the CEG, $r_{n, p}$ is 1 when the node is inside a circumference with center on the well and radius equal to the range of the semivariogram model in the $p$ parameter, $r_{n, p}$ is 0 when the node is outside the circumference (Eq. 10);

$$
f_{w, p}=\frac{\alpha_{w}}{i e_{w, p} \times i n w_{w, p}}
$$

where $f_{w, p}$ represents the $w$ well factor for the $p$ parameter $(E q .11)$;

$$
f f_{w}=\sum_{p=1}^{n p} f_{w, p} \alpha_{p}
$$

where $f f_{w}$ represents the $w$ well final factor, $n p$ represents the total number of parameters considered in the network design.

In the case study, it is proposed that $S F=f f_{w}$.

\section{Results}

\section{Case study: hydrogeological setting}

In order to evaluate the performance of the proposed methodology, it was applied for the design of a monitoring network in the "El Bajío" Region of Central Mexico (Fig. 4). The Bajío Region, specifically the Irapuato-Valle aquifer has become recently a focus of attention due to the intensive water extraction regime for agricultural, population, and industrial use. Groundwater extraction (about $600 \times 10^{6} \mathrm{~m}^{3} / \mathrm{year}$ ) through more than 2900 production wells in the area supports the water supply for more than 900,000 inhabitants in urban and rural areas, the irrigation of approximately 60,000 hectares and the water consumption for a refinery, a power production plant and several industrial parks (Comisión Nacional del Agua, 2015; Esteller et al., 2011; Gómez and Sandoval, 2004). The rock units in the study area include a sequence of Mesozoic plutonic and vulcano-sedimentary rocks affected by several metamorphism stages and Tertiary intrusive rocks outcropping in the Sierra de Guanajuato located at the North of the study area that constitutes the hydrogeological basement. The Tertiary sequence include volcanic (ignimbrites, lava flow and tuffs) and continental sedimentary rocks (conglomerates and basin fill sediments). The Oligocene volcanic sequence is comprised of andesite and rhyolite; the overlying Miocene and Pliocene volcanic rocks are mainly andesite and basalt associated with the Mexican Neo-volcanic Belt (Nietosamaniego et al., 2012). From the Oligocene, the Sierra de Guanajuato underwent a rapid uplift, the main geologic structures are NW-SE trending normal faults, displacing 
more than $500 \mathrm{~m}$ the Oligocene volcanic sequence (Gómez et al., 1989; Nietosamaniego, 1990). During this stage of deformation, several faults were reactivated, the N-S (Taxco-San Miguel de Allende fault) and NE-SW trending directions, together with the "El Bajío" Fault with NW-SE trend, formed half grabens, leading the formation of the "El Bajío" region (Botero-santa et al., 2015). At the same time, the erosion from the mountains led to transfer clastic material to the graben structure. The deposition of basin fill sediments in the graben structure produced a granular permeable regionally unconfined aquifer with a maximum thickness of $350-400 \mathrm{~m}$. Basin fill sediments are inter-bedded poorly consolidated fluvio-lacustrine sediments, including sands, interbedded sandy-clay and silts. From pumping test data, typical hydraulic conductivity values for that aquifer are 1 to $10 \mathrm{~m}$ /day (Júnez-Ferreira et al., 2016a). The Tertiary volcanic rocks are cut by a set of NW-SE and N-S normal faults, creating the possibility of a fractured heterogeneous aquifer (200-300 m thickness). The basaltic Pliocene rocks outcropping in the southern portion of the study area are in contact with the basin fill sediments, they confirm an unconfined aquifer with hydraulic conductivity values from 6 to $18 \mathrm{~m}$ /day (Júnez-Ferreira et al., 2016a). The Oligocene and Miocene volcanic rocks below the basin-fill sediments can also constitute a deep aquifer, fractured conditions along the NW-SE trending structures have been identified in deep wells (600-700 $\mathrm{m}$ deep) producing thermal groundwater (well-head temperature $35-45^{\circ} \mathrm{C}$ ).

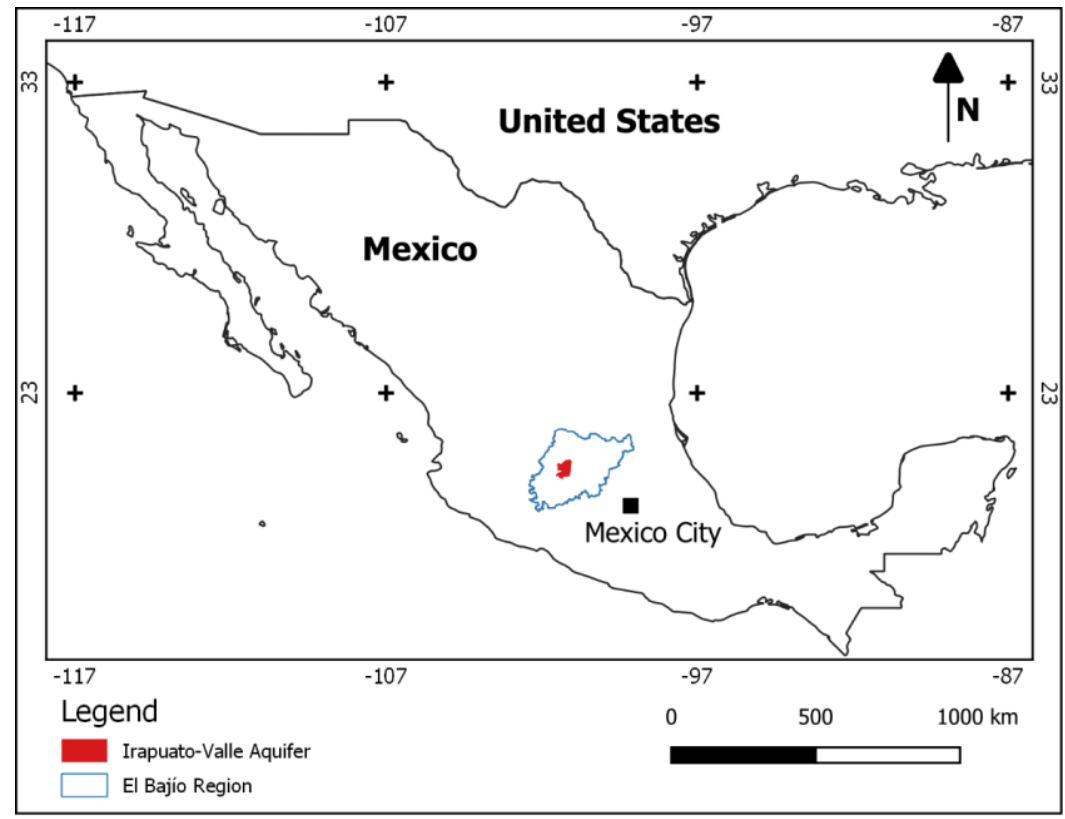

Figure 4. Location map of the study area. (Sources: Simplified El Bajio Region map modified Suárez-mota and Villase, 2015; Irapuato-Valle Aquifer from National Water Information System, 2019; countries boundaries from Tapiquén, 2019)

A sampling campaign for groundwater quality determination was carried out in December 2003 for laboratory measurement of 20 physicochemical parameters and in situ measurements of six field parameters (Júnez-Ferreira et al., 2016a), a total of 140 water samples were taken in production wells from the study area. A map displaying the sampled wells is presented in Figure 2 (UTM coordinates datum WGS84, Zone 14N). Wells ranging from 46 to $700 \mathrm{~m}$ deep (mean $180 \mathrm{~m}$, standard deviation $115 \mathrm{~m}$ ), most of 
them screened along the saturated length of the well, promoting intra-well artificial mixing. This implies that sampled water represents a mixture of several water-bearing layers. It was identified that water in recharge areas is $\mathrm{HCO}_{3}-\mathrm{Ca}$ dominant type $(650 \mathrm{mg} / \mathrm{L}$ of total dissolved solids in average). Along the groundwater flow, water chemistry evolves to dominant $\mathrm{HCO}_{3}-\mathrm{Mix}$ and $\mathrm{HCO}_{3}-\mathrm{Na}$. Groundwater quality analysis indicates the contribution of geogenic and anthropogenic contamination sources. The volcanic rocks, especially those of rhyolitic composition and the basin fill sediments derived from them, are potential trace element sources specifically for Arsenic. The water samples were analyzed for arsenic composition (mean $0.011 \mathrm{mg} / \mathrm{L}$, max. $0.083 \mathrm{mg} / \mathrm{L}), 35 \%$ of the samples exhibit concentrations in excess of the WHO guideline value $(0.010 \mathrm{mg} / \mathrm{L})$ (Fig. $5 a$ ). Dissolved arsenic is usually found as arsenic (III) in reducing environments, which usually develops at some depth within aquifers, while near the water table oxic condition prevails (Appelo and Postma, 2005). There is a lack of vertical water quality profiles information in wells, for this reason it is not possible to demonstrate the existence of any vertical transition between oxic and anoxic conditions in the tapped aquifer. However, aerobic and oxic conditions (dissolved oxygen above $1 \mathrm{mg} / \mathrm{L}$, Eh values above $100 \mathrm{mV}$ ) were detected in all the groundwater samples, suggesting that oxic conditions should prevail in most of the water bearing geologic formations tapped by the production wells. Considering that the sample depth could be assigned to mid-well screen depth, no correlation between sample depth and arsenic values was identified $\left(\mathrm{R}^{2}=0.07\right)$, indicating that dissolved arsenic is not explained by desorption from $\mathrm{Fe}$-(hydr)oxide minerals in reducing conditions (Fig. 5b). Most of the high arsenic water samples are associated with $\mathrm{HCO}_{3}-\mathrm{Na}$ dominant type, indicating that leaching from volcanic rocks with rhyolitic composition is a major control. Evidence from north-central Mexico suggests that dissolution of volcanic glass of felsic composition seems to be the dominant process for arsenic release into groundwater (Banning et al., 2012); the concentration in the central and northwest region of the study area seem to be derived from this source. The basin fill sediment constitutes an additional source; arsenic values above the WHO drinking water standard in the southwest region of the study area are probably derived from the basin fill sediments. Decarbonatization of basin-fill sediments could constitute an additional process for arsenic mobilization (Banning et al., 2012). The identification of groundwater impacted from anthropogenic sources, considered water types such as $\mathrm{Cl}-$ $\mathrm{Mg}$, Mixed-Ca, Mixed-Na, and $\mathrm{SO}_{4}$-Mixed; they exemplify impacted groundwater by diffuse contamination. Impact of diffuse contamination produced by irrigation can be evaluated with a combination of indicators, such as chloride, sulphate, nitrate, phosphate among others (Cardona et al., 2008). Chloride is a conservative solute; it is useful to detect the infiltration of diffuse contamination from agricultural activities. In addition, electrical conductivity is a function of the total concentration and charge of the ions; the relationship between them is approximately linear in most of the cases. The relation between chloride and electrical conductivity for water samples from the study area is shown in Figure 6. The characteristics of the local surface water and wastewater are presented as an additional reference. Despite the scatter, there is an evident general trend for most of the samples, suggesting that infiltration of wastewater modify to some extent groundwater composition. A few samples are not following the general trend, especially high electrical conductivity values with low chloride values; for these samples high alkalinity values (>500 $\left.\mathrm{mg} / \mathrm{L} \quad \mathrm{CaCO}_{3}\right)$ linked with low nitrate 
concentration (about 4-5 mg/L N-NO 3 ), suggest a limited influence of irrigation return flow or wastewater infiltration.

From the above considerations, the methodology proposed in this paper was applied for the design of an optimal groundwater quality monitoring network oriented to characterize the spatial distribution within the study area of only three parameters of the database presented in Júnez-Ferreira et al. (2016a): arsenic, chloride and electrical conductivity. Six cases were analyzed: 1) $V=1$ and $W=0$ within the OF ("100-0"), 2) $V=99.999$ and $W=0.001$ ("99.999-0.001"), 3) $V=99.995$ and $W=0.005$ ("99.995 $0.005 "), 4) \mathrm{V}=99.99$ and $W=0.01$ (“99.99 - 0.01”), 5) $V=0.5$ and $W=0.5$ ("50 50") and 6) $V=0$ and $W=1$, but in this case the optimization procedure is applied in such a manner that the highest priority in wells is assigned to the highest estimate error variance ("Worst" case). For the six cases $\alpha_{w}=\alpha_{p}=1$.
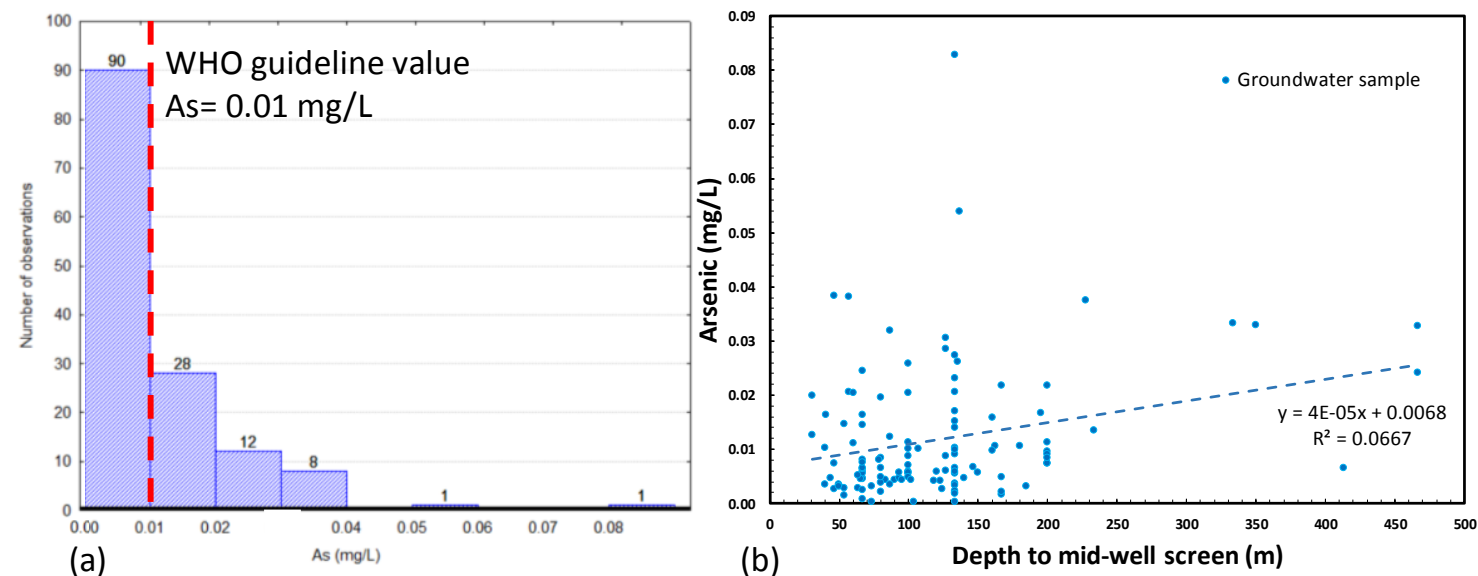

Figure 5. Arsenic analysis in a) the number of samples for groups and the reference of the $W H O$, in b) the correlation between concentration and well depth

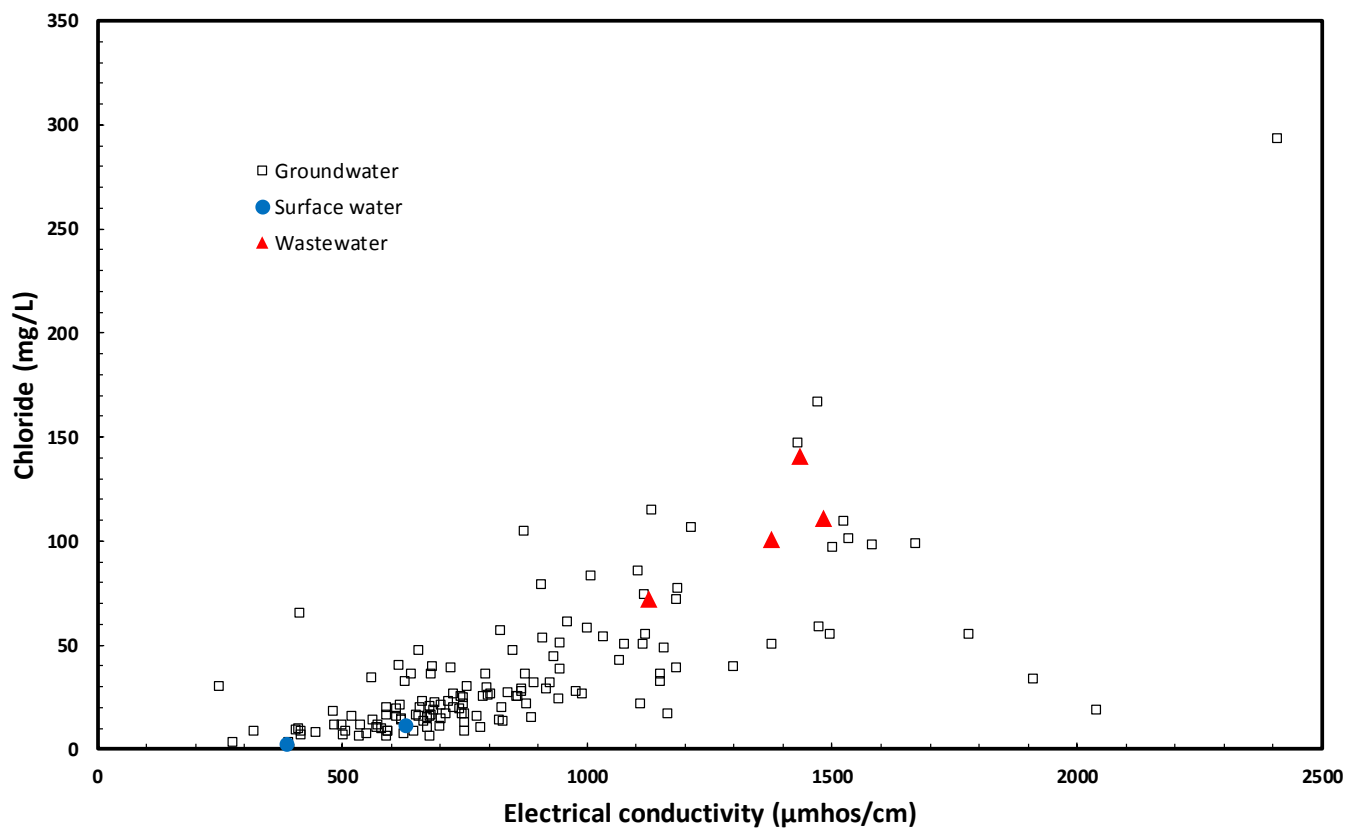

Figure 6. Correlation between chloride and electrical conductivity 


\section{Geostatistical analyses}

As a result of the geostatistical analyses carried out to the selected groundwater quality parameters, semivariogram models for each parameter were obtained (Table 1). With these models, covariance matrices were derived and normalized for each parameter and used in the optimization process, using the CEG and the CSG values.

Table 1. Semivariogram models used for the generation of the groundwater monitoring network

\begin{tabular}{c|c|c|c|c}
\hline Parameter & Model & Nugget $\left(\mathbf{u}^{2}\right)^{*}$ & Sill $\left(\mathbf{u}^{\mathbf{2}}\right)^{*}$ & Range $(\mathbf{m})$ \\
\hline Electrical conductivity & Spherical & 0 & 125097 & 6792 \\
Arsenic & Spherical & $6.5 \times 10^{-5}$ & 0.000142 & 4685 \\
Chloride & Spherical & 60.98 & 1490 & 6515 \\
\hline
\end{tabular}

$* u$ in $(\mathrm{mg} / \mathrm{L})$ for arsenic and chloride, in $(\mu \mathrm{mhos} / \mathrm{cm})$ for electrical conductivity

\section{Discussion}

The methodology proposed by Júnez-Ferreira et al. (2016a) considered the selection of sampling points by choosing the well positions that minimize the estimate error variance of the selected indicator parameters with the option to include priority zones according to the groundwater quality data. The optimization process is supported by a Kalman filter to calculate WJT. The comparison between Júnez-Ferreira et al. (2016a) and the methodology proposed in this paper was carried out for various weighted values of the Kalman filter and the ponderation map proposed also in this new methodology. For the first case $(100-0)$, the 100 indicates the percentage used for the calculations of the WJT with the Kalman filter and 0 the percentage of the SF; meaning that this is the equivalent of the Júnez-Ferreira et al. (2016a) methodology.

Figure 7 shows the percentage of reduction of the initial WJT that is obtained on the CEG each time a new well is added to the monitoring network for the six analyzed cases. The fastest reduction in the WJT is, as expected, produced for case " $100-0$ ", on the other hand, the lowest reduction corresponds to what we called the "Worst" case. The introduction of non-zero values to the SF produces a slower reduction in the WJT compared to the " $100-0$ ", it can be shown that assigning the same weight to both functions of the OF ("50 - 50") results in a reduction of the WJT that is found approximately in the middle of the " $100-0$ " and the "Worst" cases. Assigning a very small weight to the SF produces almost the same estimates than in the optimal case in terms of the estimate uncertainty value ("100 - 0"); however, a different set of wells is now selected.

Figure $8 a$ shows that for the " 100 - 0" case, the first 10 positions are selected mainly at the central part of the cloud of the sampling stations, when the optimal monitoring network includes 30 positions; it extends to cover a larger area of the cloud of available sampling stations. However, it does not include positions in the periphery. An optimal monitoring network with 50 positions reaches some of the peripheral sampling positions with a high density at the central zone of the cloud.

Even though a priority order was assigned to all the monitoring wells, only those with the highest priority will be monitored in an optimal scheme since they achieve the highest reduction in the estimation grid uncertainty. In order to compare the set of wells selected for cases "100 - 0", “99.999-0.001", “99.995-0.005", "99.99-0.01”, and 
"50 - 50", an analysis of Figure 8 was done, where 10, 30 and 50 wells comprise the selected monitoring networks for each case. The resulting monitoring network for the "worst" case is not analyzed further; their WJT values were only used as a reference in Figure 7, to visualize how close the different cases are to the best and worst possible estimation scenarios.

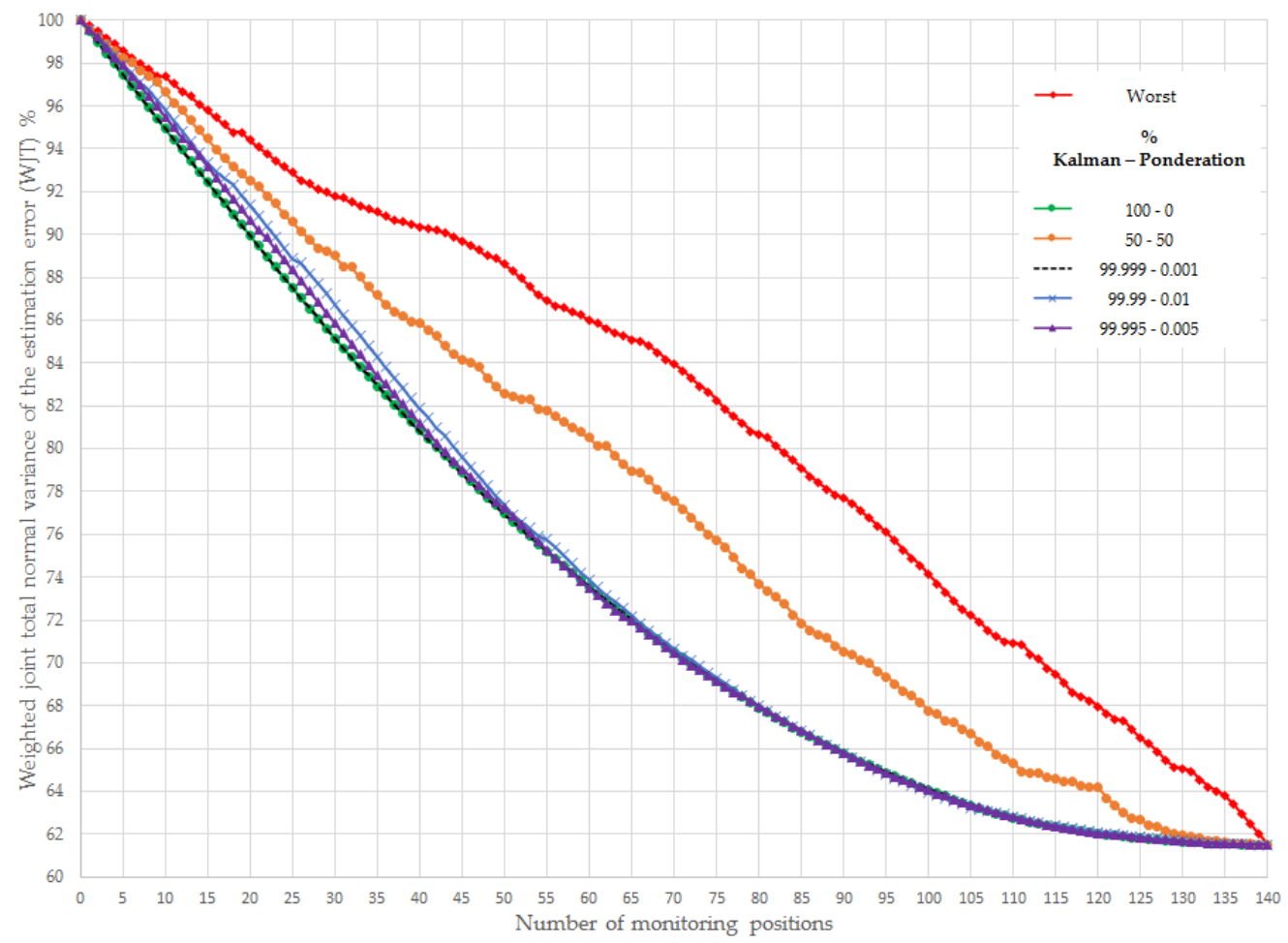

Figure 7. Comparison of the WJT (\%) vs number of monitoring positions

When analyzing the "99.999 - 0.001" case (Fig. 8b), the first 10 positions are slightly biased to the south, including some of the peripheral wells. When 30 positions are selected, the wells are more homogeneously distributed within the cloud of points, but unlike the " $100-0$ " case, the peripheral well with a priority value of 27 is included. With 50 positions, the same spatial coverage than the " $100-0$ " case is virtually obtained.

For the "99.995 - 0.005" case shown in Figure $8 c$, the first 10 positions are notoriously biased to the extreme Southern part; only the position with a priority value of 9 is located at the Northwest. For 30 positions, the distribution is considerably better, with small areas uncovered at the central part. Finally, with 50 positions, the spatial coverage is better than in cases "100-0", "99.999-0.001", considering various wells at the Western periphery. The increase in the WJT value when selecting 50 wells for the "99.995 - 0.005 " and the " $100-0$ " cases is of $0.25 \%$, this means that the loss of information is minimum for this alternative.

In Figure $8 d$ it can be shown that for the "99.99-0.01" case, the first 10 and 30 selected positions are more biased to the south compared to the previously analyzed cases. When 50 positions are included in the monitoring network, the coverage is very similar to Figure $8 c$; however, the WJT value has increased in $0.40 \%$ with respect to the "100-0" case. 
The "50 - 50" case (Fig. 8e), is clearly biased to the selection of wells along the Southern periphery when 10 positions are included in the monitoring network. The selection of 30 wells now includes the Western periphery and one well is selected at the North. When 50 positions are selected, the monitoring networks is denser at those peripheral zones, leaving the central part of the cloud uncovered.

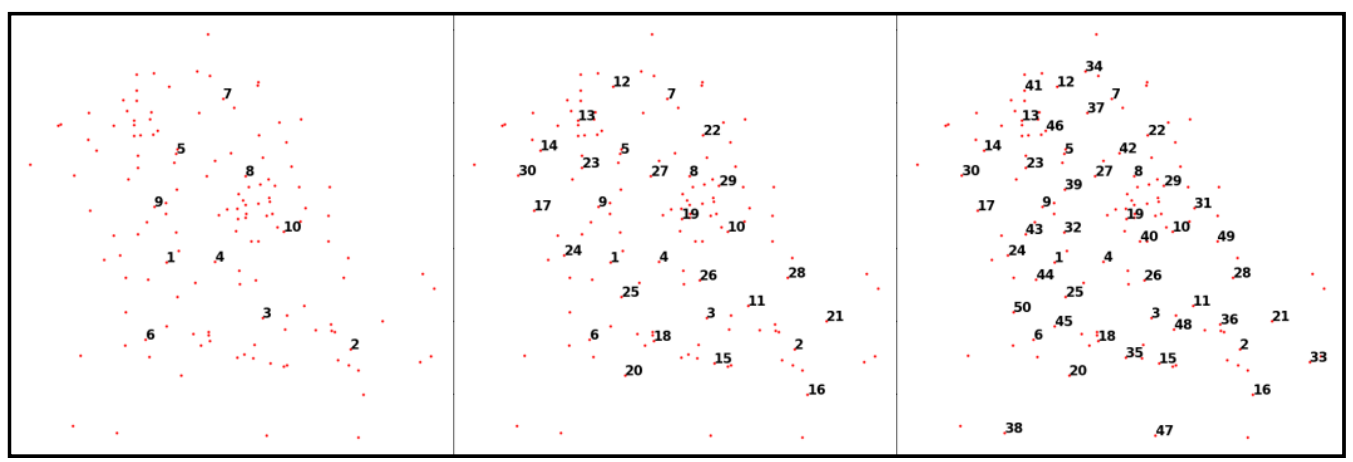

(a)

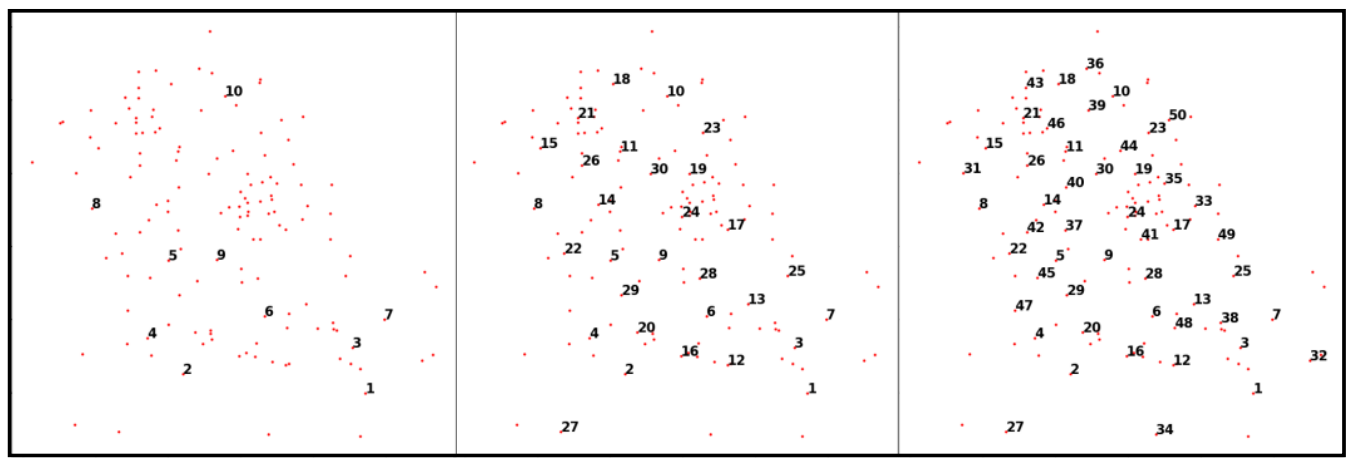

(b)

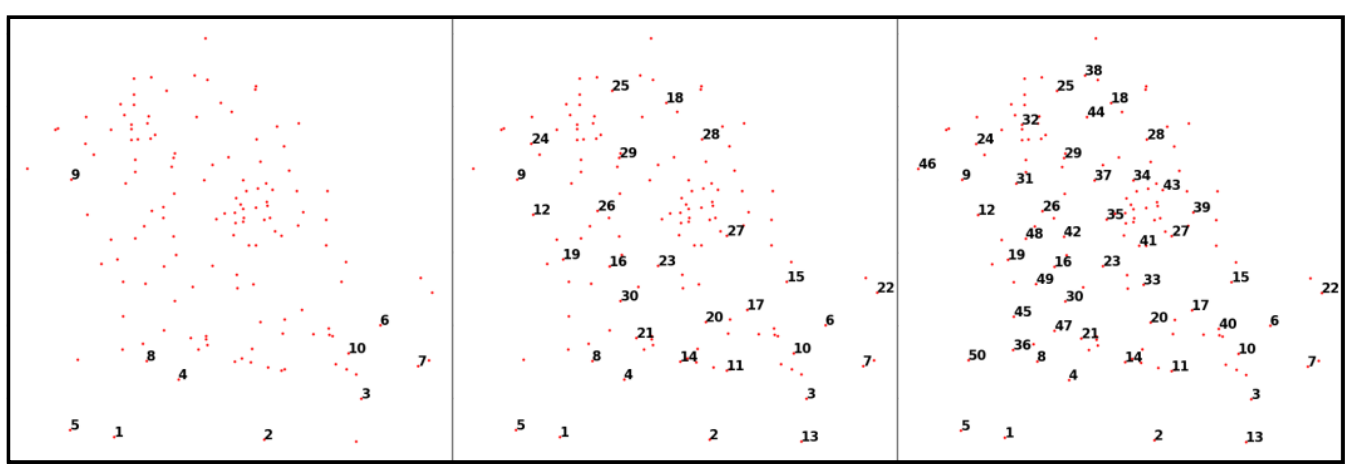

(c)

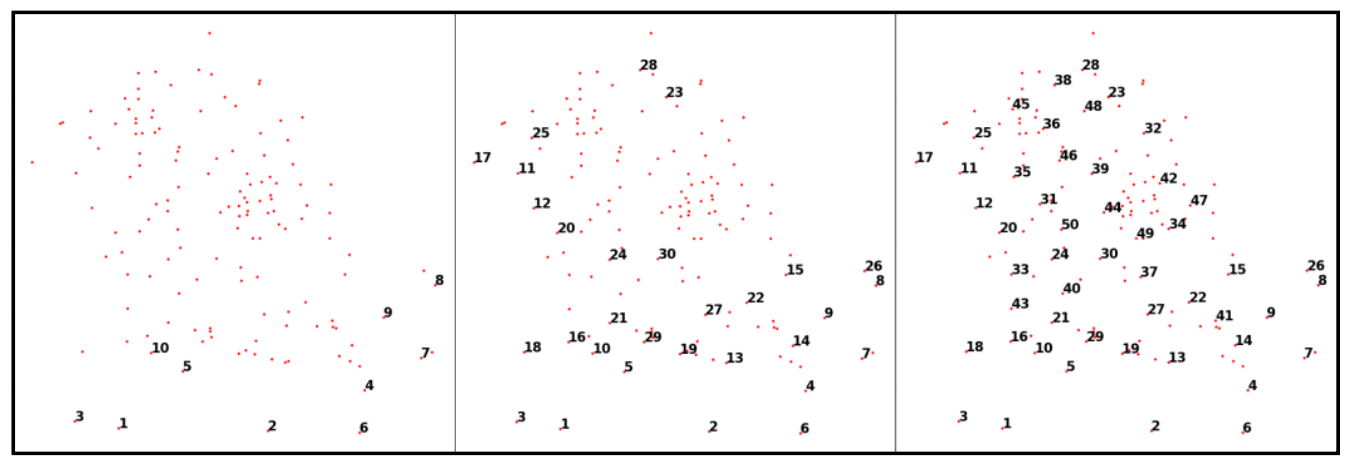

(d) 


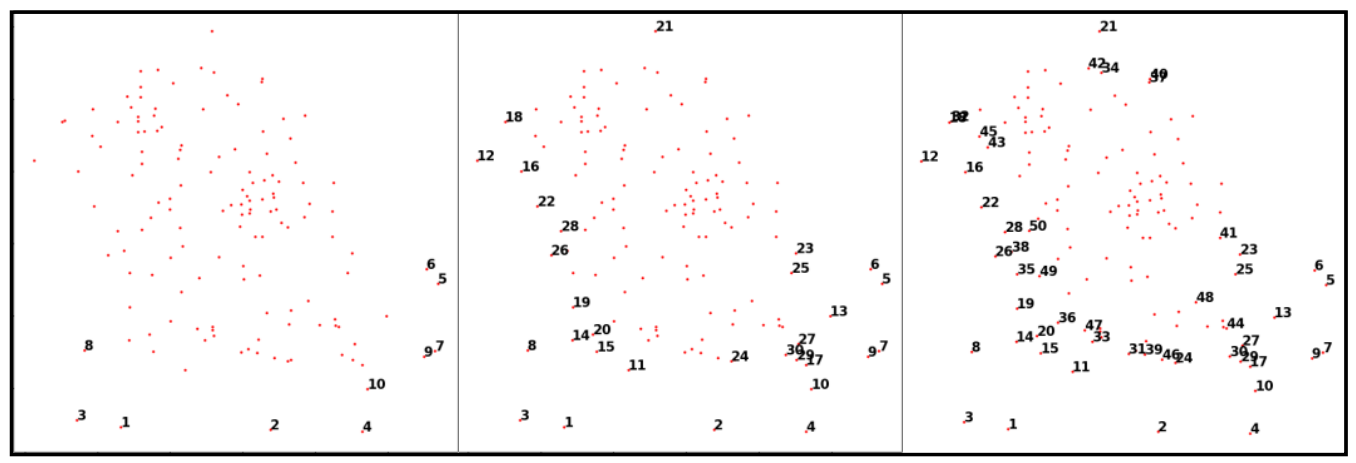

(e)

Figure 8. Groundwater monitoring networks and priority order for cases: a) "0-100", b) “0.001-99.999", c) "0.005-99.995", d) "0.01-99.99" and e) "50-50"

\section{Conclusions}

Various methodologies for the design of optimal groundwater monitoring networks are based on the reduction of the estimated error variance of the variable(s) involved in the design; these estimates are obtained over an estimation grid. In most cases, the shape of the estimation grid is square or rectangular; therefore, at poorly sampled peripheral areas, the estimates are extrapolations. On the other hand, these methodologies are biased to assign a higher priority to those wells that have more influence over a larger number of nodes of the estimation grid, thus assigning a low priority to those wells closer to the periphery of the estimation grid (Júnez-Ferreira et al., 2016a).

When the design is oriented to reduce the estimated error variance only, without assigning specific weights to the nodes of the estimation grid, the monitoring network could fail in covering some pre-defined priority zones or wells with valuable information. Therefore, it is necessary to evaluate alternative designs to consider those areas or sites of interest, minimizing the loss of information when estimating with the selected optimal monitoring network.

The proposed methodology includes a new algorithm for the definition of the estimation grid that takes into account the shape of the cloud of available sampling positions, trying to avoid extrapolation. The inclusion of a supplementary function in the optimization procedure allows the monitoring design to achieve a better spatial coverage, especially at the periphery of the estimation grid, without having a significant loss of information. The objective function considers also the assignment of weights to the wells; this aspect is important when some of them have been previously identified as relevant.

Through this methodology, it is possible to analyze alternative designs in which the spatial coverage of the monitoring networks changes, but its estimates are close to the optimal in terms of the estimate error variances.

Geochemistry evolution, along with groundwater flow in thick heterogeneous aquifers can be interpreted by specific methodologies; hydrogeochemistry is useful to solve questions of origin and attenuation of geogenic and anthropogenic contaminants. The proposed methodology considers statistical techniques to analyze the spatial distribution of specific water quality parameters as a result of sampling campaigns. In this regard, the understanding of groundwater chemical evolution and/or impacts of 
diffuse contamination with the monitoring network is beyond of the scope of the proposed methodology. This methodology is useful for the selection of the most convenient set of sampling stations in selected areas from a number of alternatives, it was specifically oriented for the implementation of drinking water monitoring networks. Once the monitoring network is designed, the collected data will include information from the whole selected area, data redundancy will be avoided and WTJ customized accordingly for example with financial resources and/or available time. The implementation of this methodology should facilitate to decision makers the classification of water quality in aquifers.

Acknowledgements. Jorge Aceves De Alba greatly appreciates the support of the Consejo Nacional de Ciencia y Tecnología (CONACyT) for a scholarship grant from August 2014 to February 2016. Jorge Aceves De Alba would also like to acknowledge the support of the Programa para el Desempeño Profesional Docente (PRODEP) for a scholarship grant from August 2016 to July 2017, as well as the reviewers for their comments and suggestions which helped us to improve this paper. This work was partially financially supported by the National Council of Science and Technology (CONACyT) through grant 294537 (Consolidación del Laboratorio Nacional de Espectrometría de Masas con Aceleradores) and CONACyT-BMBF (Federal Ministry of Education and Research, Germany) through grant 0207586.

\section{REFERENCES}

[1] Alizadeh, Z., Mahjouri, N. (2017): A spatiotemporal Bayesian maximum entropy-based methodology for dealing with sparse data in revising groundwater quality monitoring networks: the Tehran region experience. - Environ. Earth Sci. 76(12): 1-15.

[2] Andricevic, R. (1990): Cost-effective network design for groundwater flow monitoring. Stoch. Hydrol. Hydraul. 4(1): 27-41.

[3] Appelo, C. a. J., Postma, D. (2005): Geochemistry, Groundwater and Pollution. 2nd Ed. A. A. Balkema Publishers, Leiden.

[4] ArcGIS, "Create Fishnet" - http://desktop.arcgis.com/en/arcmap/10.3/tools/datamanagement-toolbox/create-fishnet.htm (accessed: 21-Oct-2018).

[5] Baalousha, H. (2010): Assessment of a groundwater quality monitoring network using vulnerability mapping and geostatistics: A case study from Heretaunga Plains, New Zealand. - Agric. Water Manag. 97(2): 240-246.

[6] Banning, A., Cardona, A., Rüde, T. R. (2012): Applied geochemistry uranium and arsenic dynamics in volcano-sedimentary basins - an exemplary study in North-Central Mexico. - Appl. Geochemistry 27(11): 2160-2172.

[7] Bode, F., Ferré, T., Zigelli, N., Emmert, M., Nowak, W. (2018): Reconnecting stochastic methods with hydrogeological applications: a utilitarian uncertainty analysis and risk assessment approach for the design of optimal monitoring networks. - Water Resour. Res. 54(3): 2270-2287.

[8] Botero-Santa, P. A., Alaniz-Álvarez, S. A., Nieto-Samaniego, Á. F., López-Martínez, M., Levresse, G., Xu, S. (2015): Origin and development of the El Bajío basin in the central sector of the Transmexican Volcanic Belt [Origen y desarrollo de la cuenca El Bajío en el sector central de la Faja Volcánica Transmexicana]. - Rev. Mex. Ciencias Geológicas 23(1): 84-98.

[9] Buja, K. (2012): Sampling Design Tool (ArcGIS 10.0). https://www.arcgis.com/home/item.html?id=ecbe1fc44f35465f9dea42ef9b63e 785 (accessed: 10-Oct-2018).

[10] Cardona, A., Carrillo-Rivera, J. J., Castro Larragoitia, G. J., Graniel-Castro, E. H. (2008): Combined use of Indicators to Evaluate Waste-Water Contamination to Local Flow Systems in Semi-Arid Regions: San Luis Potosi. - In: Rivera, J. J. C., Guerrer, M. A. O. 
(eds.) Mexico in Groundwater Flow Understanding from Local to Regional Scale. 1st Ed. CRC, London, pp. 85-104.

[11] Cardona, A., Banning, A., Carrillo-Rivera, J. J., Aguillón-Robles, A., Rüde, T. R., Aceves de Alba, J. (2018): Natural controls validation for handling elevated fluoride concentrations in extraction activated Tóthian groundwater flow systems: San Luis Potosí, Mexico. - Environ. Earth Sci. 77(4): 121.

[12] Comisión Nacional del Agua (2015): Update of the Average Annual Availability of Water in the Irapuato-Valle Aquifer (1119), State of Guanajuato [Actualización de la disponibilidad media anual de agua en el acuífero Irapuato-Valle (1119), Estado de Guanajuato]. - Comisión Nacional del Agua, Mexico.

[13] CONAGUA (2017): Water Statistics in Mexico [Estadísticas del agua en México]. CONAGUA, Ciudad de México.

[14] Esteller, M. V., Rodríguez, R., Cardona, A. (2011): Evaluation of hydrochemical changes due to intensive aquifer exploitation : case studies from Mexico. - Environ Monit Assess 184(9): 5725-41.

[15] Esquivel, J. M., Morales, G. P., Esteller, M. V. (2015): Groundwater monitoring network design using GIS and multicriteria analysis. - Water Resour. Manag. 29(9): 3175-3194.

[16] Gómez, J. A. M., Sandoval, R. (2004): Use of groundwater in the Irapuato-Valle de Santiago aquifer region (Mexico) and its impact on the hydrogeological system [Uso del agua subterránea en la región acuífera Irapuato-Valle de Santiago (México) y su impacto sobre el sistema hidrogeológico]. - Boletín Geológico y Min. 115): 311-318.

[17] Gómez, J. J. A., Gómez, J. M. A., Samaniego, Á. F. N. (1989): Considerations about the tectonic evolution during the Cenozoic of the Sierra de Guanajuato and the southern part of the Mesa Central [Consideraciones acerca de la evolución tectónica durante el Cenozoico de la Sierra de Guanajuato y la parte meridional de la Mesa Central]. - Rev. del Inst. Geol. UNAM 8(1): 33-46.

[18] Herrera, G. S., Pinder, G. F. (2005): Space-time optimization of groundwater quality sampling networks. - Water Resour. Res. 41(12): 25-49.

[19] Hosseini, M., Kerachian, R. (2017a): A Bayesian maximum entropy-based methodology for optimal spatiotemporal design of groundwater monitoring networks. - Env. Monit Assess 189: 1-24.

[20] Hosseini, M., Kerachian, R. (2017b): A data fusion-based methodology for optimal redesign of groundwater monitoring networks. - J. Hydrol. 552: 267-282.

[21] Jiang, S., Fan, J., Xia, X., Li, X., Zhang, R. (2018): An effective Kalman filter-based method for groundwater pollution source identification and plume morphology characterization. - Water (Switzerland) 10(8). DOI: 10.3390/w10081063.

[22] Júnez-Ferreira, H. E., Herrera, G. S. (2013): A geostatistical methodology for the optimal design of space-time hydraulic head monitoring networks and its application to the Valle de Querétaro aquifer. - Environ. Monit. Assess. 185(4): 3527-3549.

[23] Júnez-Ferreira, H. E., Herrera, G. S., Gonzalez-Hita, L., Cardona, A., Mora-Rodriguez, J. (2016a): Optimal design of monitoring networks for multiple groundwater quality parameters using a Kalman filter: application to the Irapuato-Valle aquifer. - Environ. Monit. Assess. 188(1): 39.

[24] Júnez-Ferreira, H., González, J., Reyes, E., Herrera, G. S. (2016b): A geostatistical methodology to evaluate the performance of groundwater quality monitoring networks using a vulnerability index. - Math. Geosci. 48(1): 255-44.

[25] Kim, G.-B. (2015): Optimal distribution of groundwater monitoring wells near the river barrages of the 4MRRP using a numerical model and topographic analysis. - Environ. Earth Sci. 73(9): 5497-5511.

[26] Kim, G.-B., Lee, K.-K., Lee, J.-Y., Yi, M.-J. (2007): Case study for determination of a water level monitoring frequency for nationwide groundwater monitoring networks in Korea. - J. Hydrol. 342(3-4): 223-237. 
[27] Kollat, J. B., Reed, P. M., Maxwell, R. M. (2011): Many-objective groundwater monitoring network design using bias-aware ensemble Kalman filtering, evolutionary optimization, and visual analytics. - Water Resour. Res. 47(2): 1-18.

[28] Li, Z., Deng, X., Wu, F., Hasan, S. S. (2015): Scenario analysis for water resources in response to land use change in the middle and upper reaches of the Heihe River Basin. Sustain. 7(3): 3086-3108.

[29] Loaiciga, B. H. A., Member, A., Member, A., Rouhani, S. (1992): Review of groundwater quality monitoring network design. - J. Hydraul. Eng. 118(1): 11-37.

[30] Luo, Q., Wu, J., Yang, Y., Qian, J., Wu, J. (2016): Multi-objective optimization of longterm groundwater monitoring network design using a probabilistic Pareto genetic algorithm under uncertainty. - J. Hydrol. 534): 352-363.

[31] Mirzaie-Nodoushan, F., Bozorg-Haddad, O. Loáiciga, H. A. (2017): Optimal design of groundwater-level monitoring networks. - J. Hydroinformatics 19(6): 920-929.

[32] National Water Information System, "National Water Information System [Sistema Nacional de Información del Agua]" - http://sina.conagua.gob.mx/sina/ (accessed: 14Apr-2019).

[33] Nieto-Samaniego, Á. F. (1990): Cenozoic faulting and stratigraphy in the southeastern part of the Sierra de Guanajuato [Fallamiento y estratigrafía cenozoicos en la parte sudoriental de la Sierra de Guanajuato]. - Rev. del Inst. Geol. UNAM 9(2): 146-155.

[34] Nieto-Samaniego, , Á. F., Ojeda-García, Á. C., Alaniz-Álvarez, S. A., Xu, S. (2012): Geology of the Salamanca region, Guanajuato, Mexico [Geología de la región de Salamanca, Guanajuato, México]. - Boletín la Soc. Geológica Mex. 64(3): 411-425.

[35] Nobre, R. C. M., Rotunno, O. C. Filho, Mansur, W. J., Nobre, M. M. M., Cosenza, C. a, N. (2007): Groundwater vulnerability and risk mapping using GIS, modeling and a fuzzy logic tool. - J. Contam. Hydrol. 94(3-4): 277-292.

[36] Singh, C. K., Katpatal, Y. B. (2017): Evaluating control of various hydrological factors on selection of groundwater-level monitoring networks in irrigated areas using a geospatial approach. - J. Irrig. Drain. Eng. 143(8): 05017003.

[37] Sizirici, B., Tansel, B. (2015): Parametric fate and transport profiling for selective groundwater monitoring at closed landfills : A case study. - Waste Manag. 38): 263-270.

[38] Suárez-Mota, M. E., Villase, J. L. (2015): The Bajio region, Mexico and the conservation of its floristic diversity. - Rev. Mex. Biodivers. 86: 799-808.

[39] Tapiquén, E. P. (2019): Efraín Porto Tapiquén Geography, GIS and Environmental Studies [Geografía, SIG y Estudios Ambientales]. - https://tapiquen-sig.jimdo.com/ (accessed: 14-Apr-2019).

[40] Uddameri, V., Andruss, T. (2014): A GIS-based multi-criteria decision-making approach for establishing a regional-scale groundwater monitoring. - Environ. Earth Sci. 71(6): 2617-2628.

[41] UN WATER, "Indicator 6.3.2 - Water quality" http://www.sdg6monitoring.org/indicators/target-63/indicators632/ (accessed: 25-Oct2018).

[42] WWAP (2016): Water and Jobs. - WWAP, Paris.

[43] WWAP (2018): Nature-Based Solutions for Water. - WWAP, Paris.

[44] XTools "XTools Pro, 18." https://help.xtools.pro/pro/18.0/en/XTools_Pro_Components/Analysis_Tools/Create_Fish net.htm (accessed: 11-Oct-2018).

[45] Yang, Y., Xu, W., Chen, J., Chen, Q., Pan, Z. (2018): Hydrochemical characteristics and groundwater quality assessment in the diluvial fan of Gaoqiao, Emei Mountain, China. Sustainability 10(12): 4507.

[46] Zhang, Y., Pinder, G. F., Herrera, G. S. (2005): Least cost design of groundwater quality monitoring networks. - Water Resour. Res. 41(8): 1-12.

[47] Zhou, Y., Dong, D., Liu, J., Li, W. (2013): Upgrading a regional groundwater level monitoring network for Beijing Plain, China. - Geosci. Front. 4(1): 127-138. 


\section{APPENDIX}

Samples

\begin{tabular}{|c|c|c|c|c|}
\hline UTM X & UTM Y & $\begin{array}{c}\text { Electrical conductivity } \\
(\mu \mathrm{mhos} / \mathrm{cm})\end{array}$ & Arsenic (mg/l) & Chloride (mg/l) \\
\hline 255942 & 2293883 & 721 & 0.02835 & 38.85 \\
\hline 258294 & 2294106 & 865 & 0.032 & 29.1 \\
\hline 264225 & 2294358 & 563 & 0.0232 & 13.8 \\
\hline 266037 & 2293737 & 698 & 0.0153 & 10.8 \\
\hline 249273 & 2284968 & 248 & 0.0034 & 29.75 \\
\hline 250397 & 2283463 & 739 & 0.0056 & 19.2 \\
\hline 247341 & 2280044 & 581 & 0.0097 & 10 \\
\hline 241239 & 2281506 & 674 & 0.0101 & 14.9 \\
\hline 260375 & 2292217 & 1113 & 0.0107 & 50.22 \\
\hline 264528 & 2288593 & 502 & 0.0069 & 6.84 \\
\hline 269331 & 2289364 & 787 & 0.0066 & 25.43 \\
\hline 254750 & 2279539 & 839 & 0.0057 & 26.9 \\
\hline 256120 & 2281124 & 802 & 0.0059 & 26.7 \\
\hline 256090 & 2282764 & 821 & 0.0051 & 13.7 \\
\hline 258212 & 2285624 & 857 & 0.0053 & 25.43 \\
\hline 266723 & 2282010 & 594 & 0.0061 & 8.56 \\
\hline 268873 & 2283108 & 876 & 0.0068 & 21.77 \\
\hline 274098 & 2279465 & 666 & 0.0085 & 13.45 \\
\hline 270904 & 2279933 & 749 & 0.0101 & 12.96 \\
\hline 261117 & 2281813 & 500 & 0.0038 & 11.25 \\
\hline 265579 & 2279966 & 678 & 0.0047 & 20.3 \\
\hline 261324 & 2272237 & 1471 & 0.0046 & 166.98 \\
\hline 259981 & 2276218 & 748 & 0.0036 & 24.7 \\
\hline 261502 & 2283669 & 482 & 0.0074 & 17.86 \\
\hline 271738 & 2270976 & 1474 & 0.0102 & 58.96 \\
\hline 272305 & 2265668 & 916 & 0.0146 & 29.1 \\
\hline 272657 & 2271001 & 977 & 0.0165 & 27.64 \\
\hline 264019 & 2265292 & 2410 & 0.0383 & 293.52 \\
\hline 261750 & 2269664 & 1105 & 0.01285 & 85.48 \\
\hline 278536 & 2287752 & 626 & 0.0042 & 7.09 \\
\hline 275567 & 2287348 & 590 & 0.0068 & 6.06 \\
\hline 276558 & 2284583 & 750 & 0.0047 & 8.31 \\
\hline 272818 & 2285517 & 647 & 0.0171 & 8.56 \\
\hline 273267 & 2282492 & 828 & 0.0232 & 13.45 \\
\hline 261399 & 2282976 & 413 & 0.0041 & 65.43 \\
\hline 257767 & 2287796 & 655 & 0.0263 & 15.9 \\
\hline 256467 & 2285587 & 572 & 0.0136 & 11.49 \\
\hline 255569 & 2285435 & 1378 & 0.00345 & 50.17 \\
\hline 255547 & 2287556 & 1000 & 0.002 & 58.21 \\
\hline 254566 & 2288936 & 663 & 0.0141 & 22.74 \\
\hline 267229 & 2274569 & 1034 & 0.0085 & 53.81 \\
\hline
\end{tabular}




\begin{tabular}{|c|c|c|c|c|}
\hline 270070 & 2266911 & 867 & 0.0206 & 27.39 \\
\hline 265991 & 2257299 & 703 & 0.0056 & 14.75 \\
\hline 264823 & 2256684 & 681 & 0.0082 & 16.38 \\
\hline 277246 & 2281242 & 570 & 0.0102 & 10.27 \\
\hline 278314 & 2278407 & 727 & 0.0205 & 26.58 \\
\hline 282529 & 2278425 & 690 & 0.0176 & 22.01 \\
\hline 258815 & 2286160 & 551 & 0.006 & 7.09 \\
\hline 255955 & 2290276 & 485 & 0.008 & 11.69 \\
\hline 254101 & 2290424 & 610 & 0.0114 & 19.56 \\
\hline 252790 & 2286848 & 628 & 0.0042 & 32.28 \\
\hline 249309 & 2288653 & 590 & 0.004 & 16.38 \\
\hline 255582 & 2286945 & 933 & 0.0044 & 44.51 \\
\hline 265851 & 2258103 & 673 & 0.0059 & 10.51 \\
\hline 263772 & 2258257 & 746 & 0.0088 & 17.12 \\
\hline 260077 & 2259299 & 703 & 0.0045 & 21.03 \\
\hline 261545 & 2263341 & 1067 & 0.0297 & 42.395 \\
\hline 257189 & 2257498 & 446 & 0.00365 & 8.055 \\
\hline 285064 & 2268748 & 1299 & 0.0103 & 39.62 \\
\hline 282307 & 2271012 & 1182 & 0.006 & 39.13 \\
\hline 282371 & 2274499 & 686 & 0.01695 & 18.91 \\
\hline 278506 & 2273692 & 925 & 0.0131 & 31.55 \\
\hline 279172 & 2275540 & 943 & 0.0081 & 24.21 \\
\hline 270591 & 2276591 & 748 & 0.0219 & 21.77 \\
\hline 269822 & 2275460 & 1119 & 0.0046 & 55.28 \\
\hline 269893 & 2274092 & 945 & 0.083 & 38.4 \\
\hline 270976 & 2274737 & 823 & 0.054 & 56.75 \\
\hline 270973 & 2274224 & 1076 & 0.0107 & 50.39 \\
\hline 269655 & 2272381 & 1149 & 0.0096 & 32.29 \\
\hline 262022 & 2252546 & 406 & 0.002 & 8.875 \\
\hline 257694 & 2255060 & 782 & 0.004 & 10.27 \\
\hline 254349 & 2256718 & 507 & 0.0034 & 8.8 \\
\hline 254400 & 2261222 & 887 & 0.0035 & 14.84 \\
\hline 257494 & 2265699 & 1779 & 0.01635 & 54.84 \\
\hline 284469 & 2265951 & 1166 & 0.0047 & 16.63 \\
\hline 283214 & 2258544 & 1117 & 0.0033 & 74.36 \\
\hline 276376 & 2258892 & 520 & 0.0066 & 15.65 \\
\hline 272009 & 2254911 & 1533 & 0.0029 & 100.77 \\
\hline 276613 & 2253958 & 615 & 0.0057 & 40.11 \\
\hline 271331 & 2278492 & 620 & 0.0218 & 14.43 \\
\hline 272962 & 2278788 & 679 & 0.0206 & 15.41 \\
\hline 274982 & 2278628 & 726 & 0.0114 & 19.81 \\
\hline 268410 & 2275364 & 874 & 0.0057 & 35.96 \\
\hline 270001 & 2277455 & 827 & 0.0205 & 19.57 \\
\hline 272675 & 2276129 & 621 & 0.0168 & 13.94 \\
\hline 270933 & 2275990 & 1430 & 0.0067 & 146.76 \\
\hline 261448 & 2278096 & 775 & 0.0049 & 15.9 \\
\hline
\end{tabular}




\begin{tabular}{|c|c|c|c|c|}
\hline 260003 & 2274766 & 792 & 0.0027 & 36.2 \\
\hline 258394 & 2275726 & 680 & 0.0077 & 6.35 \\
\hline 257289 & 2273581 & 1158 & 0.0147 & 48.76 \\
\hline 279012 & 2262127 & 611 & 0.0103 & 15.41 \\
\hline 280594 & 2258783 & 1523 & 0.0123 & 109.58 \\
\hline 285398 & 2256122 & 1582 & 0.0044 & 97.84 \\
\hline 274367 & 2254234 & 590 & 0.0032 & 19.57 \\
\hline 273276 & 2260493 & 682 & 0.0071 & 36.2 \\
\hline 269754 & 2255053 & 2040 & 0.0089 & 18.83 \\
\hline 272189 & 2256803 & 945 & 0.0091 & 50.88 \\
\hline 270786 & 2255466 & 1910 & 0.0027 & 33.37 \\
\hline 251411 & 2268482 & 960 & 0.0178 & 61.15 \\
\hline 254443 & 2265954 & 1495 & 0.0315 & 54.845 \\
\hline 253651 & 2269050 & 859 & 0.0384 & 25.44 \\
\hline 256054 & 2271954 & 1213 & 0.0092 & 106.65 \\
\hline 266727 & 2268190 & 1670 & 0.0026 & 98.82 \\
\hline 273817 & 2244339 & 756 & 0.0023 & 30.08 \\
\hline 286457 & 2244021 & 991 & 0.0074 & 26.67 \\
\hline 287199 & 2249886 & 796 & 0.0052 & 29.35 \\
\hline 286441 & 2253231 & 892 & 0.0095 & 31.55 \\
\hline 285147 & 2253929 & 848 & 0.0038 & 47.29 \\
\hline 283668 & 2254647 & 559 & 0.0016 & 34 \\
\hline 295339 & 2266495 & 1501 & 0.0024 & 96.86 \\
\hline 296876 & 2264452 & 537 & 0.0007 & 11.5 \\
\hline 252791 & 2271746 & 797 & 0.0112 & 25.93 \\
\hline 282816 & 2258695 & 1009 & 0.0017 & 82.9 \\
\hline 270132 & 2265073 & 1182 & 0.0112 & 71.9 \\
\hline 276607 & 2260779 & 1131 & 0.0029 & 114.6 \\
\hline 282733 & 2259587 & 907 & 0.0007 & 79.2 \\
\hline 276186 & 2253776 & 642 & 0.0021 & 36.2 \\
\hline 255951 & 2291694 & 716 & 0.0048 & 22.8 \\
\hline 257925 & 2288696 & 658 & 0.0032 & 19.9 \\
\hline 260031 & 2268069 & 1184 & 0.0197 & 77.2 \\
\hline 265749 & 2299445 & 276 & 0.001 & 3.2 \\
\hline 272667 & 2292812 & 632 & 0 & 11.1 \\
\hline 272632 & 2292422 & 390 & 0 & 3.2 \\
\hline 267827 & 2290531 & 535 & 0.0019 & 6.3 \\
\hline 245432 & 2287054 & 593 & 0.0046 & 8.7 \\
\hline 245118 & 2286870 & 712 & 0.0045 & 16.8 \\
\hline 249504 & 2275210 & 751 & 0.005 & 17 \\
\hline 265846 & 2258531 & 1109 & 0.0099 & 21.4 \\
\hline 253236 & 2244695 & 410 & 0.00035 & 10 \\
\hline 247158 & 2245650 & 417 & 0.0035 & 6.6 \\
\hline 248184 & 2255261 & 619 & 0.0023 & 20.9 \\
\hline 294946 & 2254438 & 320 & 0.00035 & 8.7 \\
\hline 296494 & 2255175 & 417 & 0.0023 & 8.3 \\
\hline
\end{tabular}



spatial coverage

$$
-10882-
$$

\begin{tabular}{l|c|c|c|c}
289764 & 2260054 & 1149 & 0.0023 & 35.9 \\
273830 & 2274505 & 872 & 0.033 & 104.9 \\
275319 & 2272939 & 684 & 0.0066 & 39.3 \\
276204 & 2272290 & 909 & 0.0242 & 53.4 \\
274578 & 2274772 & 657 & 0.0333 & 47.6 \\
274275 & 2276426 & 743 & 0.0376 & 25 \\
274206 & 2276950 & 650 & 0.0328 & 16.3 \\
\hline
\end{tabular}

